Elsevier Editorial System(tm) for Fusion Engineering and Design

Manuscript Draft

Manuscript Number: FUSENGDES-D-12-00344

Title: Thermo-mechanical analysis of Wendelstein 7-X plasma facing components

Article Type: SOFT 27 SI

Keywords: Wendelstein, thermo-mechanical, W7-X, plasma facing components

Corresponding Author: Mr Xuebing Peng,

Corresponding Author's Institution:

First Author: Xuebing Peng

Order of Authors: Xuebing Peng; Victor Bykov; Matthias Köppen; Minyou Ye; Joris Fellinger; Alan Peacock; Michael Smirnow; Jean Boscary; Andrey Tereshchenko; Felix Schauer

Abstract: The stellarator experiment Wendelstein 7-X (W7-X) is designed for stationary plasma operation (30 minutes). Plasma facing components (PFCs) such as the divertor targets, baffles, heat shields and wall panels are being installed in the plasma vessel (PV) in order to protect it and other invessel components. The different PFCs will be exposed to different magnitude of heat loads in the range of $100 \mathrm{~kW} / \mathrm{m} 2$ to $10 \mathrm{MW} / \mathrm{m} 2$ during plasma operation. An important issue concerning the design of these PFCs is the thermo-mechanical analysis to verify their suitability for the specified operation phases. A series of finite element (FE) simulations has been performed to achieve this goal. Previous studies focused on the test divertor unit (TDU) and high heat flux (HHF) target elements. The paper presents detailed FE thermo-mechanical analyses of a prototype HHF target module, baffles, heat shields and wall panels, as well as benchmarking against tests. 
Mr.

Max Planck Institute for Plasma Physics,

EURATOM Association,

Wendelsteinstr. 1, 17491

Greifswald, Germany

14 September 2012

Dear Dr. Ing.Olaf,

Please accept the attached manuscript of the paper, named Thermo-mechanical analysis of Wendelstein 7-X plasma facing components, for SOFT-27 special issue. The paper is about the thermo-mechanical analysis of Wendelstein 7-X plasma facing components, including the high heat flux divertor targets, baffles, heat shields and wall panels, in order to verify their suitability for steady state operation.

I greatly appreciate you taking time to read this letter and the paper, and am look forward to hearing from you.

Best regards

Sincerely yours,

Xuebing Peng. 


\section{Research Highlights}

- Thermo-mechanical analysis of HHF divertor module TM-H09 shows that it can withstand heat loads of $10 \mathrm{MW} / \mathrm{m}^{2}$ in steady state when the supports was optimized accordingly.

- FE calculations indicate that the tiles of baffles and heat shields can withstand stationary heat loads of $250 \mathrm{~kW} / \mathrm{m}^{2}$, but that the pulse length of plasma operation must be limited depending on the number of full load $\left(500 \mathrm{~kW} / \mathrm{m}^{2}\right)$ cycles.

- Gap requirements for wall panels during assembly were defined based on several FE calculations. 


\title{
Thermo-mechanical analysis of Wendelstein 7-X plasma facing components
}

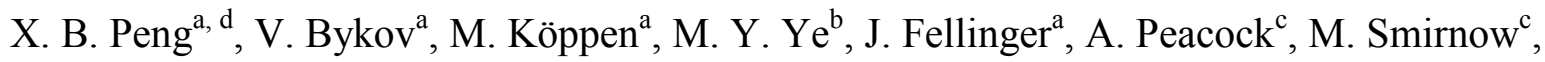 \\ J. Boscary ${ }^{c}$, A. Tereshchenko ${ }^{a}$, F. Schauer ${ }^{a}$ \\ ${ }^{a}$ Max Planck Institute for Plasma Physics, EURATOM Association, Wendelsteinstr. 1, 17491 Greifswald, Germany \\ ${ }^{b}$ School of Nuclear Science and Technology, University of Science and Technology of China, Jinzhai Road 96, 230026, \\ Hefei Anhui, P.R. China \\ ${ }^{c}$ Max-Planck-Institut für Plasmaphysik, EURATOM Association, Boltzmannstraße 2, 85748 Garching, Germany \\ ${ }^{d}$ Institute of Plasma Physics, Chinese Academy of Sciences, Shushanhu Road 350, 230031, Hefei Anhui, P.R. China
}

\begin{abstract}
The stellarator experiment Wendelstein 7-X (W7-X) is designed for stationary plasma operation (30 minutes). Plasma facing components (PFCs) such as the divertor targets, baffles, heat shields and wall panels are being installed in the plasma vessel (PV) in order to protect it and other in-vessel components. The different PFCs will be exposed to different magnitude of heat loads in the range of $100 \mathrm{~kW} / \mathrm{m}^{2}$ to $10 \mathrm{MW} / \mathrm{m}^{2}$ during plasma operation. An important issue concerning the design of these PFCs is the thermo-mechanical analysis to verify their suitability for the specified operation phases. A series of finite element (FE) simulations has been performed to achieve this goal. Previous studies focused on the test divertor unit (TDU) and high heat flux (HHF) target elements. The paper presents detailed FE thermo-mechanical analyses of a prototype HHF target module, baffles, heat shields and wall panels, as well as benchmarking against tests.
\end{abstract}

Keywords: Wendelstein, thermo-mechanical, W7-X, plasma facing components

\section{Introduction}

The stellarator experiment W7-X being constructed in Greifswald, Germany, is designed for stationary plasma operation $(30 \mathrm{~min})$ with steady state heating of up to $10 \mathrm{MW}$ ECRH and $10 \mathrm{~s}$ pulse heating power of up to $20 \mathrm{MW}$ with additional NBI and ICRH [1]. The PFCs $[2,3]$ as shown in figure 1 comprise the divertor targets (shown in magenta), baffles (brown), heat shields (blue), wall panels (cyan) and minor others (grey). They are being installed in the PV in order to protect it and other in-vessel components behind them from the convectional/radiative heat coming from the plasma. All these PFCs need to be actively water cooled during stationary operation. However, in view of the technical challenges of the HHF divertor targets, it was decided for the first phase of operation to use the simpler inertially and radiatively cooled TDU and to limit the operation to short plasma pulses [4, 5]. Except for the divertor targets, all the other PFCs will be installed at the beginning as designed for stationary operation and connected to the internal water cooling circuit but not cooled unless required. After about two years of operation, the TDUs will be replaced by the HHF divertor targets.

The design of the PFCs needs to be checked by thermo-mechanical analysis in order to verify their suitability for the specified operation phases. A series of FE simulations has been performed to achieve this goal. Previous studies focused on the TDU and HHF target elements (TEs) as presented in [5]. This paper concentrates on recent results and issues of thermomechanical studies on the PFCs for stationary operation.
During stationary operation, the different PFCs will receive heat loads of different types (convection and/or radiation) and magnitudes due to their different positions $[6,7]$ relative to the plasma, as shown in Table 1. Detailed thermo-mechanical analyses of the PFCs under these heat loads are presented in following Sections.

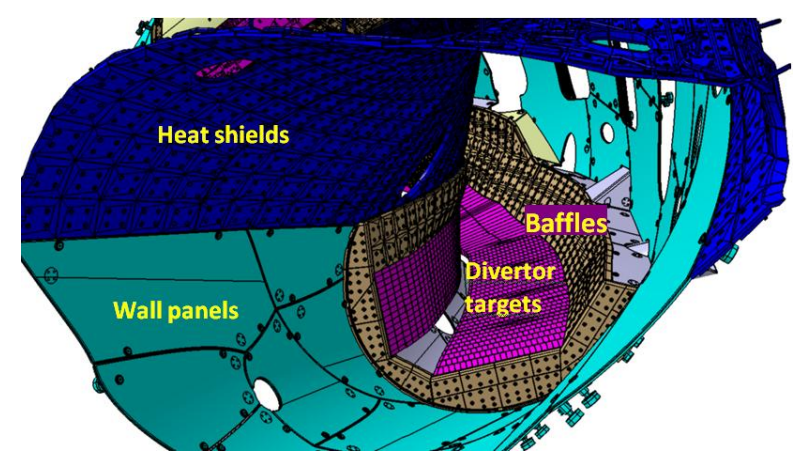

Fig. 1. PFCs, toroidal view at triangle cross-section

\section{HHF divertor targets}

The HHF divertor system consists of ten divertor units, two per each of the five symmetric modules of the machine. Each divertor unit has ten target modules. Each module is composed of $8-12$ TEs and in total there are 890 TEs for the whole divertor system [8]. A prototype was developed for the horizontal HHF target module 09 (TM-H09), see figure 2, with twelve TEs. Each TE is $250 \mathrm{~mm}$ long and $55 \mathrm{~mm}$ wide and has ten $\sim 7 \mathrm{~mm}$ thick CFC tiles bonded onto the $\mathrm{CuCrZr}$ heat sinks $(3 \mathrm{~mm}$ interlayer) [9]. These TEs are bolted to two stainless steel (SS) support rails which are attached to the PV. 
Table 1: Heat loads on PFCs during stationary operation phase

\begin{tabular}{|c|c|c|c|c|}
\hline \multirow[t]{2}{*}{ PFCs } & \multirow{2}{*}{$\begin{array}{l}\text { Type of } \\
\text { load }\end{array}$} & \multirow{2}{*}{$\begin{array}{l}\text { Average } \\
\text { heat } \\
\text { load, } \\
\mathrm{kW} / \mathrm{m}^{2}\end{array}$} & \multicolumn{2}{|c|}{ Local peak heat load } \\
\hline & & & $\begin{array}{l}\text { Value, } \\
\mathrm{kW} / \mathrm{m}^{2}\end{array}$ & $\begin{array}{l}\text { Spatial } \\
\text { extension, cm }\end{array}$ \\
\hline $\begin{array}{l}\mathrm{HHF} \\
\text { divertor }\end{array}$ & Convection & 3000 & 10000 & $\begin{array}{l}(8-15)^{\mathrm{a}} \\
\times 150^{\mathrm{b}}\end{array}$ \\
\hline Baffles & Radiation & 250 & 500 & $10^{\mathrm{a}} \times 150^{\mathrm{b}}$ \\
\hline $\begin{array}{l}\text { Heat } \\
\text { shields }\end{array}$ & $\begin{array}{l}\text { Radiation } \\
\text { with some } \\
\text { convection }\end{array}$ & 250 & 500 & $10^{\mathrm{a}} \times 100^{\mathrm{b}}$ \\
\hline $\begin{array}{l}\text { Wall } \\
\text { panels }\end{array}$ & Radiation & 100 & $200^{c}$ & $\begin{array}{l}20^{\mathrm{a}} \times \\
(300-400)^{\mathrm{b}}\end{array}$ \\
\hline
\end{tabular}

(a) Poloidal extension; (b) Toroidal extension; (c) This heat load is $10 \mathrm{~s}$ pulse, the others are continuous.

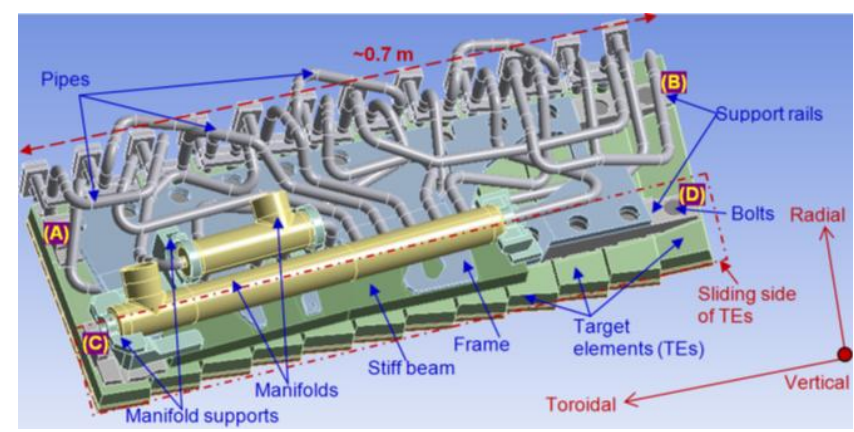

Fig. 2. Global FE model of HHF divertor TM-H09, view from the plasma vessel side

The twelve TEs are actively water cooled and arranged in six parallel circuits, two by two in series with three pipes for the connection between themselves and the manifolds. The manifolds are connected to the main invessel pipe work at one side (not shown in figure 2). At the other side they are supported by a SS frame and a stiff beam which in turn are attached to the two support rails. Nickel (Ni) adapters are used between the SS pipes and the $\mathrm{CuCrZr}$ heat sinks in order to obtain reliable joints. The TEs are fully fixed to the support rail at the side where they are connected to the cooling pipes, while at the other side they can slide radially relative to the other support rail. One of the two sides of the manifolds can move toroidally relative to the manifold supports. The stiff beam can slide radially relative to the support rail.

A 3D global FE model as shown in figure 2 was created for TM-H09 to perform thermo-mechanical analyses with the main purpose to estimate deflections, thermal stresses and requirements for module attachment. The temperature dependent material properties of $\mathrm{CFC}$, interlayer, $\mathrm{CuCrZr}$ and $\mathrm{SS}$, and the orthotropic thermal conductivity and thermal expansion coefficients for CFC were used. Table 2 shows the temperature dependent properties of the materials.

The thermal loads and boundary conditions (BCs) were: (a) heat flux of $10 \mathrm{MW} / \mathrm{m}^{2}$ applied onto the top surfaces of the central four CFC tiles of each TE; (b) heat transfer coefficient from the cooling wall of the heat sink to the cooling water [10] which is dependent on the average film temperature at constant cooling water temperature of $60^{\circ} \mathrm{C}$; (c) radiation from the heated top surfaces of the $\mathrm{CFC}$ tiles to ambient $\left(200^{\circ} \mathrm{C}\right)$.
The thermo-mechanical loads were the body temperature distribution from thermal calculation and 2.5 $\mathrm{MPa}$ water pressure. The mechanical $\mathrm{BCs}$ were applied to the end areas (marked as (A), (B), (C) and (D) in figure 2) of the two support rails. Two different mechanical load cases were investigated: Firstly, load case 1 where toroidal sliding in the fixation areas (B), (C) and (D), and radial sliding in the fixation areas (C) and (D) were allowed. Secondly, load case 2 where in addition all rotational degrees of freedom were released for the fixation areas (A), (B), (C) and (D).

Table 2: Temperature dependent properties of the materials

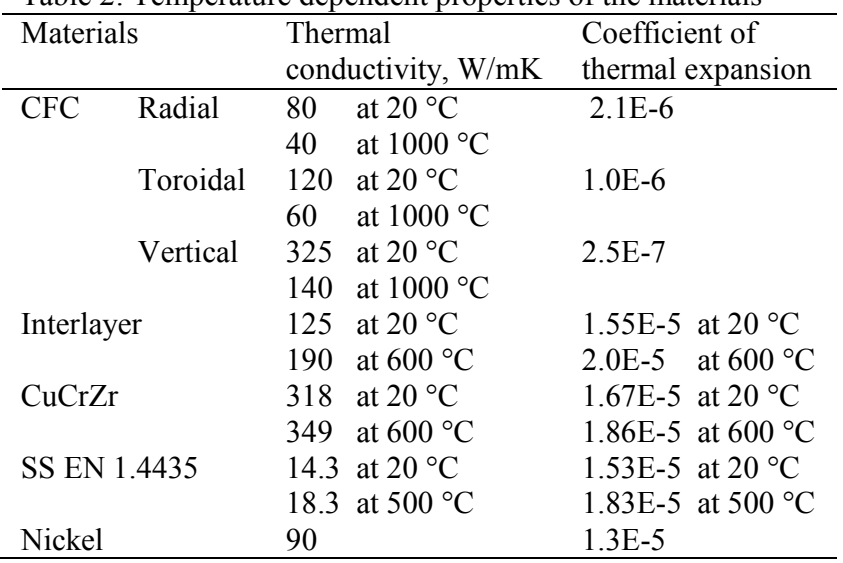

The thermal calculation shows that the maximum temperatures of the $\mathrm{CFC}$ tiles, interlayers and $\mathrm{CuCrZr}$ heat sinks are $911^{\circ} \mathrm{C}, 481{ }^{\circ} \mathrm{C}$ and $321{ }^{\circ} \mathrm{C}$, respectively, which correspond to the experimental results [11]. The temperatures of the other components are lower than $70{ }^{\circ} \mathrm{C}$.

In the elastic calculation of load case 1, von-Mises stresses in the support rails are higher than $1000 \mathrm{MPa}$ in a large area, which is far beyond the limit of $525 \mathrm{MPa}$ (secondary stress limit $3 \mathrm{~S}_{\mathrm{m}}$ ) for SS EN 1.4435 at $70{ }^{\circ} \mathrm{C}$. After the release of the rotations in the fixation areas (load case 2), the stresses are reduced significantly. The maximum stress in one of the support rails is $409 \mathrm{MPa}$. The maximum stress in the other support rail is still high $(820 \mathrm{MPa})$, but the stress higher than $525 \mathrm{MPa}$ is observed only in a very small region. The support rail is not expected to be damaged because the level of stress will decrease as soon as some local plastic deformation occurs in this region. The maximum stresses in the cooling pipes, manifolds, manifold supports, stiff beam and frame are $209 \mathrm{MPa}, 348 \mathrm{MPa}, 279 \mathrm{MPa}, 138 \mathrm{MPa}$ and $314 \mathrm{MPa}$, respectively. The maximum stress in the $\mathrm{Ni}$ adapter is $65.8 \mathrm{MPa}$, which is acceptable. The stresses in the CFC tiles and $\mathrm{CuCrZr}$ heat sinks are lower than the thermal stress limits for the corresponding materials. The vertical displacements of the TM-H09 TEs are in the range of $0.48 \mathrm{~mm}$ upwards, and $1.1 \mathrm{~mm}$ downwards (figure 3), which can be compensated by adjustment. The maximum rotational displacement in the four fixation areas is about $0.2^{\circ}$.

The results reveal that the TM-H09 can withstand heat loads of up to $10 \mathrm{MW} / \mathrm{m}^{2}$ in steady state when the supports allow rotation and translation. The design of the 
supports was optimized accordingly. Two other types of HHF target modules with minor deviation of geometric parameters were studied too, using a simple model with only one TE. The investigation indicates that both modules do not have structural problems under heat loads of $10 \mathrm{MW} / \mathrm{m}^{2}$.

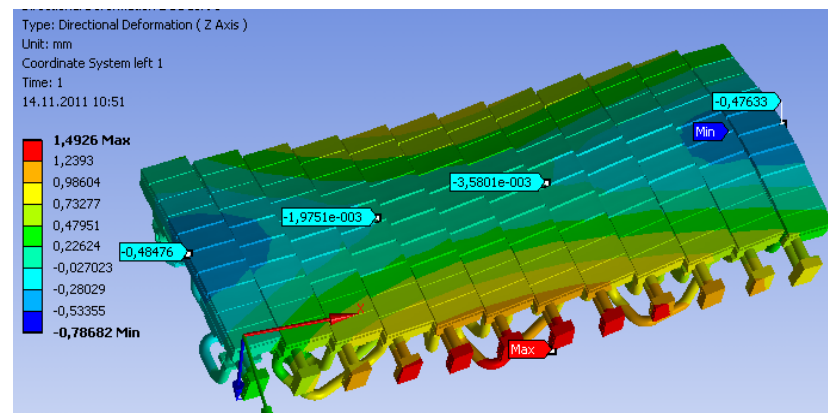

Fig. 3. Vertical displacement (mm) of TM-H09 (load case 2), view from the plasma side

\section{Baffles and heat shields}

The baffles and heat shields are modules [12] of a series of graphite tiles bolted to $\mathrm{CuCrZr}$ heat sinks which are brazed on $\emptyset 12 \times 1 \mathrm{~mm}$ common SS cooling pipes. A $1 \mathrm{~mm}$ layer of Sigraflex is squeezed between each tile and heat sink to improve the thermal contact (figure 4).

The baffle module is supported by a stiff support frame whereas the heat shield module is attached to the PV via more flexible supports. Figure 5 shows a typical baffle module and heat shield module.

Both steady state and transient thermo-mechanical FE analyses of a tile (figure 4) were performed based on the heat loads listed in Table 1 . The displacements at the end of the pipe were not constrained.

Two significant issues were found in the course of analyses: (1) the large temperature gradient in the pipe results in high stresses and (2) the cooled but still rather hot back surfaces of graphite tiles lead to heat loads on the PV significantly exceeding the design limit.

The results showed that the tile can withstand the average heat load for steady state operation, but that under local peak heat load it can only be operated in pulses of up to $45 \mathrm{~s}$ to limit the thermal stress in the cooling pipe.

The temperature gradient is mainly determined by $A_{q} / A_{\text {pipe }}$, the area ratio of heated area of graphite tile to the contact area between the cooling pipe and the heat sink. The most critical tiles are the outermost ones at the module edge. The relations $A_{q} / A_{\text {pipe }}$ as well as $A_{q} / A_{\text {sigra }}$ (which is the ratio of the tile to the heat sink areas) for the edge tiles are shown in figure 6. On the other hand, the edge tiles are less critical with respect to thermal deformation of the cooling pipe, which is less restrained in such tiles than in the tiles in the middle of the module. The support structure also affects the mechanical behavior of the tiles.
Taking all these factors into consideration, an FE model of one baffle module and an FE model of one heat shield module were created to study the overall thermomechanical response of these modules. The results of the calculations showed unacceptable thermal stress in the cooling pipe of the baffle module even under steady state loads of $250 \mathrm{~kW} / \mathrm{m}^{2}$ due to stiff restraint of the thermal deformation of the cooling pipe by the support structure. The flexible support structure of the heat shield module did not lead to significantly increased stresses.

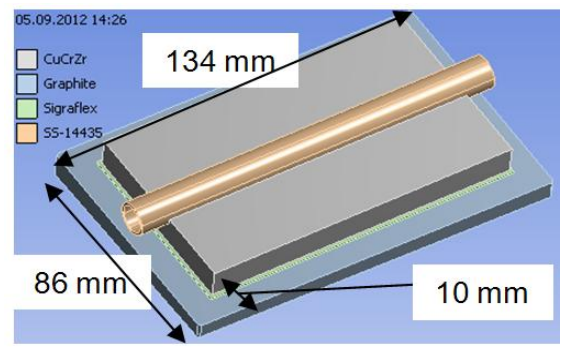

Fig. 4. Structure of a baffle and heat shield tile

(a)

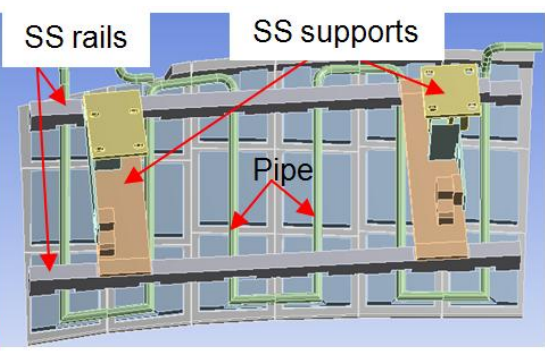

(b)

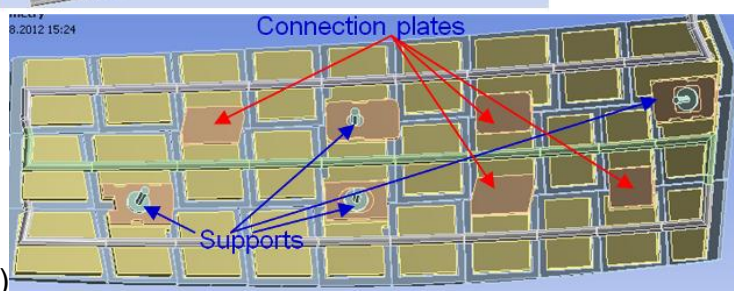

Fig. 5. Support structure of a typical baffle module (a) and heat shield module (b)

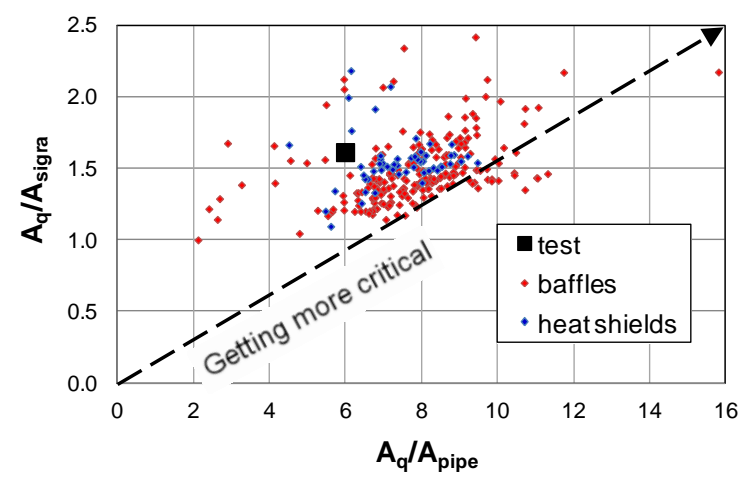

Fig. 6. Area ratios of heated area to cooled area and heated area to Sigraflex area for W7-X edge tiles and the tested tile

However, a thermal test showed that the tile can survive 500 cycles of design load heating with pulse lengths of $200 \mathrm{~s}[3,13]$. The tested tile showed almost the same relation $A_{q} / A_{\text {pipe }}$ as the FE calculated single tile, but this value was not conservative as compared to the edge tiles in W7-X (figure 6). 
To clarify the mismatch between the test results and the elastic analysis results, elastic plastic analyses were carried out on a single tile using a temperature distribution that was successfully benchmarked against the test results [13]. The primary result is that the plastic strain in the cooling pipe under test conditions is within the low cycle fatigue limit for the tested 500 cycles. For W7-X, 60000 plasma shots are expected. Assuming all of them to be full load cycles, the allowed pulse length of a local peak heat load would be $40 \mathrm{~s}$ which is coincidentally consistent with the result of FE elastic analysis of a single tile. In reality, most of the shots will not be full load cycles, i.e. the allowed full load pulse length can be much higher. The pulse lengths depending on heat loads and corresponding cycle numbers are currently being evaluated.

The temperature of the back surfaces of graphite tiles is heavily affected not only by the $A_{q} / A_{\text {pipe }}$ ratio but also by the $A_{q} / A_{\text {sigra }}$ ratio. Thermal calculation results indicate that the heat load on the PV coming from tiles is higher than the limit of $1.9 \mathrm{~kW} / \mathrm{m}^{2}$. A potential solution by installing a radiation shield at the backside of the tile clamped onto the cooling pipe is considered in [14].

\section{Wall panels}

A wall panel (WP) consists of two SS plates of $5 \mathrm{~mm}$ and $1.5 \mathrm{~mm}$ thickness which are laser welded together forming a cooling channel [6]. The structural reliability was validated by burst testing and transient heat flux testing [6]. An important issue is the definition of gaps required between WPs in order to avoid collisions and overload of the supports to the PV. Large expansion and deformation during baking and plasma operation due to heat loads, internal pressure, and PV deformation were considered. Three representative wall panels were selected for thermo-mechanical analyses, which were performed for two load cases. The normal plasma operation load case includes $100 \mathrm{~kW} / \mathrm{m}^{2}$ heat load, $5813 \mathrm{~W} / \mathrm{m}^{2} \mathrm{~K}$ heat transfer coefficient in the cooling channel at constant cooling water temperature of $80^{\circ} \mathrm{C}$, and $2 \mathrm{MPa}$ cooling water pressure. The baking load case considers $160{ }^{\circ} \mathrm{C}$ uniform temperature at the same water pressure. Figure 7 shows the resulting deformation of the largest wall panel during normal operation. Directional displacements were extracted from FE calculations for every edge of the WPs in a local coordinate system. Based on this information, the gap requirements to be checked during assembly were defined in toroidal and poloidal directions separately, depending on the curvature of the WPs, the distances between all relevant support pairs of a series of WPs, and the available sliding space between the panels and their supports.

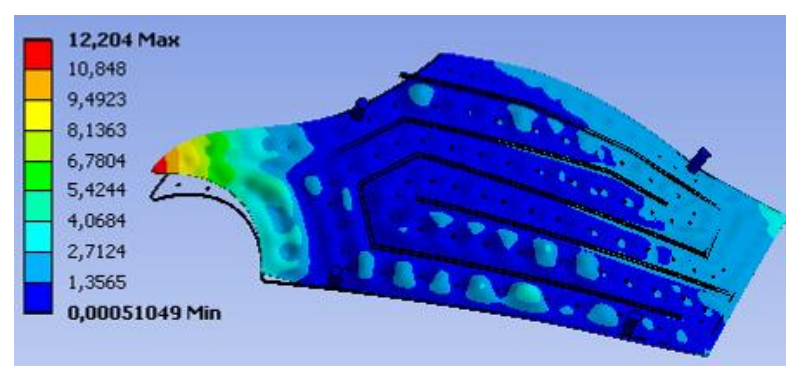

Fig. 7. Deformation ( $\mathrm{mm}$ ) of a wall panel during operation, view from the plasma vessel side

\section{Conclusion}

A series of FE analyses has been performed to verify and eventually improve the design of various PFCs which are exposed to heat loads in the range of $100 \mathrm{~kW} / \mathrm{m}^{2}$ to $10 \mathrm{MW} / \mathrm{m}^{2}$.

The detailed thermo-mechanical analysis of HHF divertor module TM-H09 shows no critical issues when it is subjected to $10 \mathrm{MW} / \mathrm{m}^{2}$ stationary heat flux. However, the supports have to be optimized with an extra flexibility. Similar modules were also studied and confirmed by FE analyses based on simplified models.

FE calculations indicate that the tiles of baffles and heat shields can withstand average steady state heat loads of $250 \mathrm{~kW} / \mathrm{m}^{2}$. But, due to high thermal stress in the cooling pipes, the pulse length of plasma operation must be limited depending on the number of full load cycles. In order to predict the operation limit of W7-X more precisely, further heat flux tests with an increased number of cycles are necessary.

Several FE calculations were done for wall panels to investigate deformations. The results are the basis for the WP gap requirements for assembly. Further analyses are ongoing on the baffles, heat shields and wall panels with respect to allowed gaps and steps in between them, relaxation of support restrictions, and non-conformities.

\section{References}

[1] H. Renner, et al., Nucl. Fusion 40 (2000) 1083.

[2] R. Stadler, et al., Fusion Eng. Des. (2009) 305.

[3] H. Greuner, et al., Fusion Eng. Des. 66-68 (2003) 447.

[4] A. Peacock, et al., Fusion Eng. Des. 84 (2009) 1475.

[5] M.Y. Ye, et al., Fusion Eng. Des. 86 (2011) 1630.

[6] A. Peacock, et al., Fusion Eng. Des. 86 (2011) 1706.

[7] R. Brakel, et al., Specification of design loads for in-vessel components of W7-X, W7-X project document, PLM: 1AC-S0005. 0.

[8] J. Boscary, et al., Fusion Eng. Des. 86 (2011) 572.

[9] H. Greuner, et al., Fusion Eng. Des. 86 (2011) 1685.

[10] H. Greuner, et al., Proceeding of 20th SOFT, vol. 1, 1998, 249-252.

[11] H. Greuner, et al., Fusion Eng. Des. 84 (2009) 848.

[12] B. Mendelevitch et al., this conference.

[13] J. Fellinger, X. Peng, Thermo-mechanical assessment of heat shields and baffles, W7-X project document, PLM: 1GXA50-T0003.0.

[14] A. Carls, et al., this conference. 